\title{
Craniometaphyseal dysplasia
}

INSERM

\section{Source}

INSERM. (1999). Orphanet: an online rare disease and orphan drug data base.

Craniometaphyseal dysplasia. ORPHA:1522

Craniometaphyseal dysplasia (CMD) is a very rare genetic bone disease characterized by progressive diffuse hyperostosis of cranial bones causing facial dysmorphism and functional repercussions, and metaphyseal widening of long bones. 